Palaeohispanica 2, (2002), pp. 201-211

\title{
PROPUESTA DE UBICACIÓN DE LOS VOLCIANOS EN EL ÁREA PREPIRENAICA
}

Francisco Pina Polo

Silvia Alfayé Villa

En el contexto de los acontecimientos que condujeron al inicio de la II guerra Púnica en el año 218, Livio ${ }^{1}$ narra la estancia de legados senatoriales en Hispania, cuya misión consistía en lograr un pacto de amistad con pueblos hispanos o, cuando menos, apartarlos de la alianza con Cartago ("Legati Romani ab Carthagine... in Hispaniam, ut adirent civitates et in societatem perlicerent aut averterent a Poenis, traiecerunt"). Livio menciona sólo dos pueblos: los bargusios y los volcianos. Los bargusios, a quienes visitaron en primer lugar los embajadores romanos, recibieron a éstos con agrado, provocando entre muchos de los pueblos que habitaban más allá del Ebro, un deseo de revuelta contra los cartagineses ("...multos trans Hiberum populos ad cupidinem novae fortunae erexerunt"). Desde el territorio de los bargusios, los legados se dirigieron al de los volcianos ("Ad Volcianos inde est ventum..."), quienes, según el autor latino, rechazaron en asamblea ("in concilio") cualquier alianza con Roma, aduciendo que difícilmente podía inspirar confianza un estado que acababa de traicionar a sus amigos saguntinos. Invitados a abandonar el territorio de los volcianos, los embajadores no volvieron a encontrar apoyo en ninguna otra asamblea en Hispania ("Inde extemplo abire finibus Volcianorum iussi ab nullo deinde concilio Hispaniae benigniora verba tulere"). En consecuencia, abandonaron Hispania y pasaron a la Galia ("Ita nequiquam peragrata Hispania in Galliam transeunt").

Independientemente de que la reconstrucción de Livio pueda contener elementos retóricos en los detalles relativos a la respuesta de los volcianos, la actuación de la embajada senatorial, que luego continuaría su recorrido por la Galia con escaso éxito, es perfectamente plausible. También lo es la existencia histórica de los volcianos, ${ }^{2}$ a pesar de que ésta es la única mención de este pueblo indígena en toda la literatura antigua, algo que, precisamente en el mismo contexto del comienzo de la

\footnotetext{
${ }^{1}$ Liv., XXI 19,6-11.

${ }^{2}$ Al respecto, véase F. Marco, “¿Volcas en Hispania?: a propósito de Livio, 21,19,6”, Études celtiques 32 (1996) 49-55.
} 
guerra Anibálica, sucede también con otros pueblos próximos a los Pirineos, los airenosios y los andosinos, citados exclusivamente por Polibio como poblaciones conquistadas por Aníbal en su marcha desde el Ebro hacia la cordillera pirenaica. ${ }^{3}$ Del texto glosado se deduce que las fuentes que manejó Livio en relación con estos acontecimientos conocían la existencia de un pueblo al que llamaban volcianos, para cuya ubicación sólo contamos con el dato de que habitaban una región situada en el norte de Hispania, presumiblemente no lejos de los bargusios.

A este respecto, no hay duda de que los bargusios habitaban una zona situada entre el río Ebro y los Pirineos, como se desprende del relato de Livio sobre la ruta seguida por Aníbal en el año 218 en su camino hacia Italia: viniendo desde Carthago Nova, el general cartaginés, tras cruzar el Ebro, sometió a ilergetes, bargusios, ausetanos, así como la región de Lacetania. ${ }^{4}$ La descripción coincide en algunos puntos con el texto de Polibio citado más arriba, quien menciona como pueblos conquistados al norte del Ebro a ilergetes y bargusios, omite a ausetanos y lacetanos, pero añade a airenosios y andosinos. Tras atravesar los Pirineos, Aníbal dejó a Hannón al mando de este territorio recién conquistado, desconfiando en especial de los bargusios, por ser amigos de Roma, información que, como hemos visto, también se desprende de su actitud ante los embajadores senatoriales según Livio. ${ }^{5}$ Existe un acuerdo general en identificar a los bargusios con el pueblo de los bergistanos que cita Livio en relación con las campañas de Catón en el año 195, ${ }^{6}$ algo que, de nuevo, confirma su ubicación al norte del Ebro.

Con toda probabilidad, Aníbal evitó en su camino hacia los Pirineos la ruta costera, más cómoda pero más peligrosa para su planes al obligarle a pasar junto a Emporion, la colonia griega aliada de Roma en la que desembarcarían las primeras tropas romanas poco después, lo que habría desenmascarado sus intenciones de llegar con la mayor rapidez posible a Italia. En consecuencia, el ejército cartaginés debió de utilizar una ruta interior, probablemente ascendiendo por el río Segre desde su desembocadura en el Ebro hasta los Pirineos, que atravesaría bien por el Coll d'Ares, bien por el Coll de La Perxa. ${ }^{7}$ Es por consiguiente a lo largo de esa ruta donde hay que situar a los bargusios o bergistanos, a los que, por homofonía con la toponimia moderna, se ubica tradicionalmente en la comarca del Bergadá, en torno a la actual población de Berga y en el valle alto del río Llobregat.

\footnotetext{
3 Pol., III 35,2.

${ }^{4}$ Liv., XXI 23,2.

5 Pol., III 35,4.

${ }^{6}$ Liv., XXXIV 16-17.

${ }^{7}$ F. Beltrán Lloris, "El año 218 a.C. Problemas en torno al comienzo de la segunda guerra púnica en la Península Ibérica", en 5 Col.loqui internacional d'arqueologia de Puigcerdà, 2326 de setembre de 1982, Puigcerdà 1984, 147-171. Chr. Rico, Pyrénées romaines. Essai sur un pays de frontière (IIIe siècle av.J.-C.-IVe ap. J.-C.), Madrid 1997, 86, propone que Aníbal habría repartido su ejército en varias unidades, una de las cuales habría atravesado los Pirineos por el alto Segre, otra u otras por pasos más orientales.

${ }^{8}$ Beltrán Lloris, "El año 218 a.C.", 162; Rico, Pyrénées romaines, 88-89.
} 
A través de las fuentes antiguas, conocemos el nombre de los diversos pueblos indígenas situados en la proximidad de los bargusios. Al norte y noroeste de ellos deben ser ubicados los airenosios y los andosinos que menciona Polibio. Nuevamente por homofonía se les adjudica respectivamente el valle de Arán a los primeros, ${ }^{9}$ y la región andorrana a los segundos, ${ }^{10}$ si bien es posible que en el momento inicial de la conquista sus territorios fueran más amplios y se extendieran hacia el sur. Al este de los andosinos hay que situar con seguridad a los cerretanos, conocidos por otras fuentes y cuyas inscripciones confirman su carácter cultural no indoeuropeo. Los cerretanos habitarían la región actual de la Cerdaña, a la que habrían dado nombre. ${ }^{11} \mathrm{Al}$ este de los bargusios se situaban los ausetanos, alrededor de su capital Auso (Vic). Al sur y al oeste, rodeando aparentemente el territorio de los bargusios, vivían los lacetanos, si incluimos entre sus ciudades a Iesso (Guissona) y Aeso (Isona). Finalmente, algo más al sur, en la zona más próxima al río Ebro, en el bajo Segre, hay que situar en este momento inicial de la conquista romana a los ilergetes, en torno a Ilerda (Lérida), ciudad que en el siglo II a.C. debió de sustituir como capital a Atanagrum, cuya ubicación exacta se desconoce.

Aun contando con el carácter en buena medida hipotético que tiene la ubicación de estos pueblos indígenas, de acuerdo con estos datos los volcianos de Livio podrían localizarse al oeste de bargusios y lacetanos, al sur de los airenosios y al noroeste de los ilergetes, con mayor probabilidad en la zona prepirenaica que en la de alta montaña, donde es improbable que una embajada romana se hubiera aventurado a buscar alianzas en el año 218 , teniendo en cuenta que el interés estratégico por ese ámbito y su definitiva conquista tardarían todavía más de un siglo en concretarse. ${ }^{12}$ Se puede suponer que, en previsión de una expedición cartaginesa, los embajadores romanos tuvieran un especial interés en atraerse la alianza de pueblos indígenas ubicados en las rutas interiores que conducían desde el Ebro a los Pirineos, en particular en la zona situada entre los ríos Cinca, Noguera Pallaresa y Segre.

Respecto al origen de los volcianos, Francisco Marco mostró convincentemente que han de ser vistos como una rama de los volcas

\footnotetext{
${ }^{9}$ Rico, Pyrénées romaines, 81-82, descarta la ubicación de los airenosios en el valle de Arán por estar demasiado alejado de la ruta seguida por Aníbal y por ser una prolongación natural del valle del Garona, hoy políticamente perteneciente a España, pero geográficamente parte de la Galia. En consecuencia, se inclina (84) por ubicarlos en el curso superior del río Segre. Ya antes otros autores (véase la bibliografía pertinente en el libro de Rico) habían propuesto otras opciones: Bosch Gimpera situó a los airenosios hacia el Noguera Pallaresa; Pita Mercé amplió su territorio hacia el Noguera Ribagorzana y el Ésera; Dupré, en cambio, lo redujo al valle de Arán en el siglo I a.C., fecha en la que Pompeyo lo habría vinculado administrativamente a la Galia.

${ }^{10}$ Rico, Pyrénées romaines, $86-87$.

${ }^{11}$ F. Marco, "Entre el estereotipo y la realidad histórica: la emergencia de los pueblos pirenaicos antiguos", en J.F. Rodríguez Neila y F.J. Navarro Santana, Los pueblos prerromanos del Norte de Hispania. Una transición cultural como debate histórico, Pamplona 1998, 62-63; Rico, Pyrénées romaines, 89-92.

${ }^{12}$ F. Beltrán Lloris y F. Pina Polo, "Roma y los Pirineos: la formación de una frontera", Chiron 24 (1994) 103-133.
} 
que habitaban el sur de la Galia o, cuando menos, como un pueblo emparentado con ellos. ${ }^{13}$ Existe constancia de que los celtas volcas se asentaron en ese territorio a lo largo del siglo III a.C., diviéndose en dos grupos, los arecómicos hacia el Ródano, y los tectósagos - cuyo origen debe situarse en Europa central- entre Cevennes y los Pirineos, con Tolosa (Toulouse) como principal ciudad, situada a orillas del río Garona, el antiguo Garumna. ${ }^{14}$ La cordillera pirenaica acabó por constituir una frontera administrativa entre Hispania y Galia a iniciativa del estado romano, pero no fue en ningún momento una barrera infranqueable, sino que, por el contrario, existió una cierta permeabilidad e intercomunicación cultural entre ambas vertientes. En consecuencia, es perfectamente plausible que un grupo de esos volcas franqueara los Pirineos y se estableciera al sur de la cordillera antes del año 218 en que Livio sitúa el acontecimiento en que son mencionados, en el contexto de los movimientos de pueblos celtas que tuvieron lugar en ese período. ${ }^{15}$ Para ello pudieron utilizar alguno de los pasos naturales de montaña entre Hispania y la parte de la Galia que fue habitada por los volcas tectósagos, por ejemplo el antes citado Coll de La Perxa.

En nuestra opinión, algunos topónimos antiguos atestiguados en la baja Ribagorza y en el Somontano oscense, podrían evidenciar tanto el parentesco de los volcianos con los volcas tectósagos - o tal vez más en concreto con los tolosates, fracción de los volcas que ocuparía la zona próxima a Tolosa-, ${ }^{16}$ como su posible ubicación en esa comarca. Se

\footnotetext{
${ }^{13}$ Marco, “¿Volcas en Hispania?”, esp.50-52; idem, "La emergencia de los pueblos pirenaicos antiguos", 61. Cf. F. Villar, Indoeuropeos y no indoeuropeos en la Hispania prerromana, Salamanca 2000, 429: "el nombre (Volciani) es idéntico al de los Volcae de las Galias y tienen la misma estructura gramatical que otros tantos ejemplos: sufijo $-k o$ - no precedido de vocal" (del mismo autor, "Indoeuropeos y no indoeuropeos en la Península Ibérica", en F. Villar y M ${ }^{\mathrm{a}}$ P. Fernández Álvarez (eds), Religión, lengua y cultura prerromanas de Hispania, Salamanca 2001, 268). La tesis de Francisco Marco ha sido aceptada por V. Kruta, Les celtes. Histoire et dictionnaire des origines à la romanisation et au christianisme, París 2000, 865: el nombre de los volcianos está "probablement apparenté à celui des Volques"; "il pourrait être une faction des Volques du Languedoc, venue s'installer au IIIe siècle av.J.-C. au sud des Pyrénées". Como Marco pone de manifiesto, no hay ninguna razón que apoye la vieja propuesta de A. Schulten (Fontes Hispaniae Antiquae 3, Barcelona 1935, 43) de relacionar a los volcianos con los etruscos, sobre la base de una supuesta vinculación con la ciudad de Vulci. Tampoco pasa de ser una mera especulación la posibilidad, apuntada por A. Tovar (Iberische Landeskunde. II. Las tribus y las ciudades de la Antigua Hispania. 3. Tarraconensis, BadenBaden 1989, 38), de que, en realidad, Livio se refiera a los *Bolscani, habitantes de Bolscan = Osca (Huesca).

${ }^{14}$ Str., IV 1,13. Cf. Kruta, Les celtes, 303-308 y 865; H. Birkhan, Kelten. Versuch einer Gesamtdarstellung ihrer Kultur, Viena 1997, 87 y 244. En particular sobre las migraciones de los volcas hacia el sur de la Galia, J.P. Mohen, "La présence celtique de La Tène dans le SudOuest de l'Europe: indices archéologiques", en P.M. Duval y V. Kruta (edd.), Les mouvements celtiques du Ve au Ier siècle avant notre ère, París 1979, 41 y 47.

${ }^{15}$ Livio distingue a los volcianos de los más conocidos volcas, a los que, en el relato de la marcha anibálica hacia Italia, califica como "pueblo poderoso" y sitúa en la Galia (XXI 26,6). Esa diferenciación, no obstante, no desautoriza la hipótesis de que se trate de pueblos celtas emparentados entre sí. Cf. Marco, “¿Volcas en Hispania?”, 50, n.5.

${ }^{16}$ Los tolosates son mencionados en dos ocasiones por César (Gall., I 10; VII 7) como una civitas dentro de la provincia Narbonense, pero hay que tener en cuenta que esto sucede unos dos siglos después de que los volcas se asentaran en la región, y su individualización puede
} 
trata de Labitolosa/Labitulosa y de Tolous, ${ }^{17}$ poblaciones en las que la similitud con el nombre de la capital de los volcas galos, Tolosa, es evidente. ${ }^{18}$ La primera ha sido identificada con total seguridad en La Puebla de Castro (Huesca). Las excavaciones en curso han mostrado que se trata de una ciudad de estructura urbanística claramente romana y de existencia relativamente corta, puesto que estuvo activa sólo entre los siglos I a.C. y II d.C., alcanzando en ese tiempo el título de municipium, cuyo nombre fue Labitolosa o Labitulosa, de acuerdo con la epigrafía conservada. ${ }^{19}$ No existe constancia de un hábitat indígena, si bien el nombre de la ciudad parece remitir a un ámbito prerromano. En cuanto a Tolous, es una mansio mencionada por el Itinerario Antonino en la vía de Ilerda a Osca. ${ }^{20} \mathrm{Ha}$ sido unánimemente identificada con el cerro de Nuestra Señora de la Alegría, unos treinta kilómetros al sur de Labitolosa en las proximidades de Monzón (Huesca), donde existe una ciudad indígena desde el siglo III a.C., que tendría continuidad como mansio en época

ser una iniciativa de la administración romana. Cf. A.L.F. Rivet, Gallia Narbonensis. Southern France in Roman Times, Londres 1988, 115-129.

${ }^{17}$ F. Villar, "Talabara, Talavera, Toledo", en I.J. Adiego, J. Siles y J. Velaza (eds.), Studia palaeohispanica et indogermanica J. Untermann ab amicis hispanicis oblata, Barcelona 1993, 287-295, especialmente 292, ha relacionado los topónimos con raíz Tol- con la hidrotoponimia palaeoeuropea de la Península Ibérica y conjetura (295) que en los hidrónimos de esta serie (con sus variantes Tal-, Tel- y Tol-) hay implicados al menos dos pueblos indoeuropeos diferentes, uno responsable de las formas con vocal radical /a/ y el otro de las formas con vocal /o/. No obstante, hay que dejar constancia de que Villar, en el citado artículo, afirma (293) que no incluye Tolosa en el mapa de distribución geográfica (295) porque, si bien podría tener la misma raíz, "su formación es menos nítida".

${ }^{18}$ La relación toponímica entre las tres poblaciones ya fue planteada por P. Moret, "Le nom de Toulouse", Pallas 44 (1996) 17-22, quien rechaza sin embargo que Tolosa tenga un origen celta y lo considera un topónimo anterior a la llegada de los volcas tectósagos, perteneciente a un sustrato aquitano no indoeuropeo. Por contra, a favor de la tesis del origen celta del nombre de Tolosa se pronuncia M. Labrousse, Toulouse antique, des origines à l'établissement des Wisigoths, París 1968, 85-86.

${ }^{19}$ A. Magallón y P. Sillières, "Labitolosa (Cerro del Calvario, La Puebla de Castro, Huesca)", Bolskan 11 (1994) 89-132 (asimismo en Bolskan 14, 1997, 117-156). En particular sobre la epigrafía del municipio, véase P. Sillières, $M^{a} A$. Magallón y M. Navarro, "El municipium Labitulosanum y sus notables: novedades arqueológicas y epigráficas", AEspA 68 (1995) 107130. Los habitantes de la ciudad son llamados tanto Labitolosani (CIL II $3008=5837$ ) como Labitulosani (cf. Bolskan 11, 1994, 124).

En lo que se refiere a los antropónimos indígenas de los pedestales de Labitolosa, F. Beltrán, "Hacia un replanteamiento del mapa cultural y étnico del Norte de Aragón", en F. Villar y M.P. Fernández, (eds.), Religión, lengua y cultura prerromanas de Hispania, Salamanca 2001, 66-67, ha señalado que "ni Neilla ni Attaeso, el cognombre de un Emilio allegado de esa misma mujer, resultan fácilmente clasificables, sin embargo el segundo, pese a estar formado sobre una base tan extendida como atta y contar con paralelos célticos, admitiría también una explicación desde el aquitano, ámbito no muy distante en línea recta de Labitolosa, en cuya onomástica está bien documentado el sufijo -so. Recuérdese que Atta parece estar comprobado también en una inscripción de Sos del Rey Católico, en las altas Cinco Villas, comarca en la que junto a nombres claramente vascónicos o célticos, se aprecia un conjunto también de difícil clasificación: Altus, Astinus, Hastatus, etc."

${ }^{20}$ It.Ant., 391,3. Cf. Mª A. Magallón, La red viaria en Aragón, Zaragoza 1987, 86-87. 
altoimperial. ${ }^{21}$ Ambas ciudades se hallan en el valle del río Cinca, en su ribera izquierda.

A partir de estos datos - ciertamente exiguos pero en nuestra opinión suficientemente significativos-, sobre la base del parentesco toponímico entre Tolosa, Labitolosa/Labitulosa y Tolous, y teniendo en cuenta la probable ubicación de los bargusios y de los demás pueblos pirenaicos conocidos en su entorno, proponemos localizar a los volcianos mencionados por Livio a lo largo del medio Cinca, al este del río, tal vez preferentemente entre el Cinca y el Ésera. Establecidos en esa región durante el siglo III a.C., habrían fundado sus propias ciudades en convivencia con los pueblos indígenas preexistentes, de los que no es preciso suponer que hubieran de abandonar ese territorio tras su llegada y asentamiento. Podemos partir de la hipótesis de que los volcianos ocuparían una zona territorialmente restringida, y que posiblemente fueron absorbidos tras el inicio de la conquista romana por alguno de los pueblos vecinos, tal vez los ilergetes. ${ }^{22}$ Esto explicaría que no volvieran a ser mencionados por las fuentes antiguas, lo cual no significa necesariamente que abandonaran el territorio que les había pertenecido hasta entonces: la supervivencia toponímica de Labitolosa y Tolous avalarían esta tesis. Sea como fuere, desde un punto de vista histórico la importancia de los volcianos fue escasa, y sólo su desabrida respuesta a los embajadores romanos ha permitido que el recuerdo de su existencia haya perdurado.

En el estado actual de nuestros conocimientos, resulta imposible determinar si los volcianos, entendidos como pueblo con una organización interna, tal y como se deduce del pasaje de Livio, pudieron llegar a habitar una zona más amplia, tal vez hacia el Noguera Ribagorzana, o si existió alguna relación con los habitantes de la zona al oeste del Cinca medio, donde se sitúan las ciudades de Barb(otum?) y Boletum. ${ }^{23}$ Es

\footnotetext{
${ }^{21}$ Se encuentra un estado de la cuestión en J.A. Asensio Esteban, La ciudad en el mundo prerromano en Aragón, Zaragoza 1995, 117 y 134-138. Cf. A. Floría Pons, "La mansión de Tolous como agente de romanización en el Cinca medio", en Simposio sobre la red viaria en la Hispania romana, Zaragoza 1990, 199-207. Tolous ha sido considerada mayoritariamente como una población habitada por ilergetes, dada la relativa cercanía de la que fue su principal ciudad desde el siglo II a.C., Ilerda. Sin embargo, ya R. Pita Merce, Ilerda ilergete, Lérida 1975, 86, vinculó el topónimo Tolous con los tolosates de la zona de Tolosa en la Galia. Asimismo, J. A. Pérez, "La vía romana de Ilerda a Osca", Bolskan 2 (1985) 122, considera que la región en torno a Tolous estuvo habitada por unos hipotéticos "tolosautes" y que su cabecera fue Labitolosa.

${ }^{22}$ Los ilergetes parecen haber sido el pueblo más expansivo tras la conquista, como se desprendería del territorio que les atribuye Ptolomeo II 6,67, que incluye entre sus ciudades Bergusia y Bérgidon, tal vez en origen poblaciones pertenecientes a los bargusios o bergistanos (además de, por ejemplo, Gallica Flavia, cuyo nombre atestigua una improbable adscripción cultural al ámbito no indoeuropeo al que se adscribe tradicionalmente a los ilergetes) (cf. Tovar Iberische Landeskunde II, 382). Un proceso similar de absorción pudo suceder con las ciudades en origen volcianas.

${ }^{23}$ Estos topónimos antiguos aparecen mencionados en un documento del siglo VI, que contiene la donación realizada por Vicente, más tarde obispo de Huesca, al monasterio de Asán, ubicado en la comarca de Ribagorza (la edición crítica de esta Cartula donationis Vicentii Diaconii fue realizada por J. Fortacín, "La donación del diácono Vicente al monasterio de Asán y su posterior testamento como obispo de Huesca en el siglo VI. Precisiones críticas para la fijación del texto", Cuadernos de Historia Jerónimo Zurita 47-48, 1983, 7-70). La donación consiste en una serie de tierras que Vicente había heredado de su familia, cuya
} 
probable el carácter indoeuropeo del topónimo Barb(otum?), cuyo desarrollo exacto es desconocido, puesto que su existencia sólo se conoce a través de un epígrafe en el que Publio Emilio Ducto es identificado como Barb(otanus?) ${ }^{24}$ Recientemente se ha propuesto como ubicación para esta ciudad el yacimiento arqueológico de Monte Cillas, en Coscojuela de Fantova (Huesca) ${ }^{25}$ donde fue hallada la inscripción mencionada, a unos pocos kilómetros al oeste de Labitolosa y al norte de Tolous. Sus restos arqueológicos, que parecen corresponder a una ciudad, se extienden cronológicamente desde el siglo I a.C. hasta el V d.C. Más al norte se ubicaría otra población, cuya forma más probable es Boletum. Su existencia se deduce del apelativo Boletanus con el que es designado Lucio Valerio Materno en dos inscripciones aparecidas asimismo en Coscojuela de Fantova. ${ }^{26}$ Esta ciudad ha sido tradicionalmente identificada con la actual Boltaña, en el Sobrarbe oscense, unos cuarenta kilómetros al noroeste de Labitolosa. La filiación lingüística del topónimo Boletum resulta dudosa, aunque se ha tendido a considerar indoeuropeo. ${ }^{27}$

localización es señalada en el texto. Dos de esas propiedades se ubican en los territorios de Caesaraugusta e Ilerda (el documento dice en concreto "in terra hilardensi"). Otras tres se sitúan "in terra labeclosano", que presumiblemente debe ser entendido como territorio de Labitolosa, "in terra boletano" e "in terra barbotano", que corresponderían con toda probabilidad a Boletum y Barb(otum?) (M. Navarro, $\mathrm{M}^{\mathrm{a}}$ A. Magallón y P. Sillières, "Barb(otum?): una ciudad romana en el somontano pirenaico", Salduie 1 (2000) 248-249). Finalmente, el diácono tenía propiedades también "in terra terrantonensi". El contexto geográfico y la semejanza toponímica hace pensar en que pueda corresponder a la actual Tierrantona (La Fueva, Huesca), unos veinte kilómetros al norte de Labitolosa. Puesto que, en cada caso, el texto del siglo VI se refiere a comarcas que estarían bajo el control administrativo de ciudades, siguiendo esa lógica debió de existir en la Antigüedad en el territorio en torno a la actual Tierrantona una civitas de nombre desconocido, como civitates eran Caesaraugusta, Ilerda, Labitolosa, Boletum y Barb(otum?).

Hay que reseñar que, junto a Tierrantona, existe un topónimo moderno Toledo de Lanata y que, al otro lado de la Sierra Ferrera, apenas cinco kilómetros al norte de Toledo de Lanata, discurre el río o barranco de la Garona, topónimo que se repite a unos diez kilómetros hacia el este, en Valle de Bardagí, donde encontramos otro barranco llamado La Garona y un punto elevado contiguo del mismo nombre. El topónimo del que procede Toledo de Lanata es conocido al menos desde el siglo XI en documentos medievales, en los que aparece con las formas Toleto, Tolet y Tolento, y Terrantona es mencionado en documentos del siglo XII (A. Ubieto, Toponimia aragonesa medieval, Valencia 1972, 190-191). En la Cueva del Forcón, ubicada en el término municipal de Toledo de Lanata, fueron hallados diversos materiales arqueológicos, entre ellos un elemento de arnés de caballo en bronce, con una decoración formada por dos cabezas laterales de jabalí y una central de caballo. Cf. F. Marco, "Caballo y jabalíes en un bronce romano de la cueva del Forcón”, Bolskan 1 (1983) 193-201. La pieza apareció aislada, de modo que es imposible extraer de ella conclusiones sobre un hipotético hábitat cercano en época antigua.

${ }^{24}$ CIL II 5841. Cf. F. Beltrán, "Epigrafía y romanización en la provincia de Huesca", UNED IV, Barbastro 1987, 28.

${ }^{25}$ Navarro, Magallón y Sillières, "Barb(otum?)" 247-272.

${ }^{26}$ CIL II 5843 Y 5845. Navarro, Magallón y Sillières, "Barb(otum?)", 256-257, realizan una nueva lectura de CIL II 5846, inscripción en la que el mismo L. Valerio Materno volvería ser denominado Boletanus. Cf. Beltrán, "Epigrafía y romanización en la provincia de Huesca", 28.

${ }^{27}$ Así lo hizo A. Holder, Alt-Celtischer Sprachschatz, vol.1, Graz 1961 ('Leipzig 1896) 476. En el mismo sentido, basándose en Holder, R. Grosse, s.v. Boletum, Kleine Pauly 1, Munich $1979,925$. 
En cualquier caso, los volcianos representarían sólo una parte de los galos que, muy probablemente, atravesaron en algún momento los Pirineos para establecerse en Hispania, bien individual, bien colectivamente. ${ }^{28}$ De hecho, una serie de topónimos antiguos y modernos existentes en la cuenca del Ebro parecen probarlo ${ }^{29}$ : Gallicus flumen (el actual río Gállego); las ciudades de Gallicum y Forum Gallorum situadas en las proximidades del río Gállego; el pagus Gallorum mencionado en dos bronces latinos hallados cerca de la actual localidad de Gallur, que conservaría el origen galo en su nombre; la abreviatura gal. (kal.) de las monedas acuñadas en la ceca de Karaues, cerca de la actual Magallón; los topónimos modernos en -dunum, de probable raigambre gala, en el valle del río Aragón (Navardún, Berdún, Gordún, tal vez Embún), en los Llanos de Urgell (Verdú) ${ }^{30}$ y en el valle de Arán (Salardú) ${ }^{31}$. Todos los datos antiguos -epigráficos, numismáticos y literarios- proceden del período de la dominación romana, y no permiten establecer ni la cronología ni el volumen del asentamiento de estos galoceltas. ${ }^{32}$ Sin embargo, su dispersión apunta a una presencia relativamente numerosa, hecho que

\footnotetext{
${ }^{28}$ F. Villar, "Hispanocelta o Celtibérico", en E. C. Polomé y C. F. Justus (eds.), Language Change and Typological Variation: In Honor of Winfred P. Lehmann on the Occasion of His $83^{\text {rd }}$ Birthday. Vol. 1: Language Change and Phonology, Washington 1999, 60-77, distingue en la Península Ibérica una variedad céltica autóctona única, los celtíberos de Celtiberia, y otro componente celta dialectalmente diferente, de origen galo, del que quedan algunos elementos. Esto lleva a Villar (74) a "considerar la posibilidad de que las incursiones de galos en la Península Ibérica no sería solamente un fenómeno tardío de época romana, sino que podría haber comenzado hacia el siglo VI a.C. o acaso algo antes".

${ }^{29}$ Cf. Marco, “Volcas en Hispania?”, 54. Kruta, Les celtes, 323, defiende la presencia de celtas procedentes de la Galia, en particular en el valle del Ebro, con posterioridad a la instalación de los volcas en el Languedoc en la primera mitad del siglo III a.C., y la pone en relación con su posible utilización militar como mercenarios. Sobre la sufijación céltica en topónimos de la zona altoaragonesa, véase F. Marco en A. Beltrán Martínez (dir.), Atlas de Prehistoria y Arqueología aragonesas, Zaragoza 1980, 62-63. Una de las conclusiones del reciente estudio de Villar, Indoeuropeos y no indoeuropeos, 424, es que el estrato indoeuropeo en el Nordeste de la Península Ibérica es muy profundo, como se apreciaría tanto por los topónimos como por los etnónimos conocidos, puesto que "el nombre de la mayoría de los pueblos allí ubicados es de etimología indoeuropea en uno o más de sus componentes".

${ }^{30}$ La posible presencia de elementos galos al sur de los Pirineos podría verse corroborada en el ámbito arqueológico por la relación existente entre las cerámicas estampilladas halladas en la comarca de los llanos de Urgel, datadas en el siglo III a.C., con otras similares en el sur de Francia. Al respecto, M. Cura-Morera, "Cerámicas con decoración impresa del Molí d'Espigol (Tornabous, Lleida)", Congreso Nacional de Arqueología, Zaragoza 2001 (en prensa).

${ }^{31}$ Cf. Villar, "Hispanocelta o Celtibérico", 61 y 73: los elementos toponímicos en -dunum "son explicables como resultado de las irrupciones de galos en la Península". Sin embargo, J. Untermann, "Lengua y poblamiento prerromano en el territorio celtibérico", en F. Burillo (ed.), III Simposio sobre los celtíberos. Poblamiento celtibérico, Zaragoza 1995, 20, rechaza como indoeuropeos los supuestos topónimos en -dunum de la región. Recientemente, J. Untermann, "La toponimia antigua como fuente de las lenguas hispano-celtas", Palaeohispanica 1 (2001) 197, resalta a escasa presencia de topónimos antiguos compuestos con el sufijo -dunum en la Península Ibérica.

${ }^{32}$ No es necesario pensar, por supuesto, en un único momento migratorio, sino tal vez mejor en un contacto continuado entre ambas vertientes de los Pirineos, que se traduciría circunstancialmente en migraciones en función de diversos factores, como la situación económica o la presión demográfica. Así, César (civ., I 51) afirma que miles de galos habían llegado a la región de Ilerda en el año 49 a.C., en el contexto del inicio de la guerra civil contra Pompeyo.
} 
debe tenerse en cuenta a la hora de estudiar su posible influencia en la sociedad, economía, religión, etc., de los pueblos indígenas que habitaban en esa zona de interrelación cultural que era la cuenca del Ebro en la Antigüedad.

\section{BIBLIOGRAFÍA}

ASENSIO ESTEBAN, J.A. (1995): La ciudad en el mundo prerromano en Aragón, Zaragoza.

Beltrán, F. (1984): "El año 218 a.C. Problemas en torno al comienzo de la segunda guerra púnica en la Península Ibérica", 5 Col.loqui internacional d'arqueologia de Puigcerdà, 23-26 de setembre de 1982, 147-171, Puigcerdà.

(1987): "Epigrafía y romanización en la provincia de Huesca", UNED IV, 19-34, Barbastro.

(2001): "Hacia un replanteamiento del mapa cultural y étnico del Norte de Aragón", Religión, lengua y cultura prerromanas de Hispania, F. Villar y Ma.P. Fernández (eds.) 61-81, Salamanca.

Beltrán Lloris, F. y PINA Polo, F. (1994): "Roma y los Pirineos: la formación de una frontera", Chiron 24, 103-133.

Beltrán Martínez, A. (dir.) (1980): Atlas de Prehistoria y Arqueología aragonesas, Zaragoza.

BIRKHAN, H. (1997): Kelten. Versuch einer Gesamtdarstellung ihrer Kultur, Viena.

CURA-MORERA, M. (en prensa): "Cerámicas con decoración impresa del Molí d'Espigol (Tornabous, Lleida)", Congreso Nacional de Arqueología, Zaragoza 2001.

FloríA PONS, A. (1990): "La mansión de Tolous como agente de romanización en el Cinca medio", Simposio sobre la red viaria en la Hispania romana, 199-207, Zaragoza.

FortACÍN, J. (1983): “La donación del diácono Vicente al monasterio de Asán y su posterior testamento como obispo de Huesca en el siglo VI. Precisiones críticas para la fijación del texto", Cuadernos de Historia Jerónimo Zurita 47-48, 7-70.

Grosse, R. (1979): s.v. Boletum, Kleine Pauly 1, 925, Munich.

Holder, A. (1961): Alt-Celtischer Sprachschatz, vol.1, Graz ( ${ }^{1}$ Leipzig 1896).

KRUTA, V. (2000): Les celtes. Histoire et dictionnaire des origines à la romanisation et au christianisme, París.

LABROUSSE, M. (1968): Toulouse antique, des origines à l'établissement des Wisigoths, París.

MAgAllón, Mª. (1987): La red viaria en Aragón, Zaragoza.

Magallón, MaA. y Sillières, P. (1994): "Labitolosa (Cerro del Calvario, La Puebla de Castro, Huesca)", Bolskan 11, 89-132.

MARCO, F. (1983): "Caballo y jabalíes en un bronce romano de la cueva del Forcón”, Bolskan 1, 193-201. 
(1996): “¿Volcas en Hispania?: a propósito de Livio, 21,19,6”, Études celtiques 32, 49-55.

(1998): "Entre el estereotipo y la realidad histórica: la emergencia de los pueblos pirenaicos antiguos", Los pueblos prerromanos del Norte de Hispania. Una transición cultural como debate histórico, J.F. Rodríguez Neila y F.J. Navarro Santana (eds), 5187, Pamplona.

MoHEN, J.P. (1979): "La présence celtique de La Tène dans le SudOuest de l'Europe: indices archéologiques", Les mouvements celtiques du Ve au Ier siècle avant notre ère, P.M. Duval y V. Kruta (eds.), 29-48, París.

Moret, P., (1996): "Le nom de Toulouse", Pallas 44, 7-23.

NAVARro, M., MAGAllón, MaA. y Sillières, P. (2000): "Barb(otum?): una ciudad romana en el somontano pirenaico", Salduie 1, 247-272.

PÉREZ, J.A. (1985): "La vía romana de Ilerda a Osca", Bolskan 2, 111-138.

PITA MERCE, R. (1975): Ilerda ilergete, Lérida.

RICO, CHR. (1997): Pyrénées romaines. Essai sur un pays de frontière (IIIe siècle av.J.-C.-IVe ap. J.-C.), Madrid.

RIVET, A.L.F. (1988): Gallia Narbonensis. Southern France in Roman Times, Londres.

Sillières, P., Magallón, MaA. y NAVArro, M. (1995): "El municipium Labitulosanum y sus notables: novedades arqueológicas y epigráficas", AEspA 68, 107-130.

TOVAR, A. (1989): Iberische Landeskunde. II. Las tribus y las ciudades de la Antigua Hispania. 3. Tarraconensis, Baden-Baden.

UBIETO, A. (1972): Toponimia aragonesa medieval, Valencia

UNTERMANN, J. (1995): "Lengua y poblamiento prerromano en el territorio celtibérico", III Simposio sobre los celtíberos. Poblamiento celtibérico, F. Burillo (ed.) 7-24, Zaragoza.

(2001): "La toponimia antigua como fuente de las lenguas hispano-celtas", Palaeohispanica 1, 187-218.

VILlAR, F. (1993): "Talabara, Talavera, Toledo", Studia palaeohispanica et indogermanica J. Untermann ab amicis hispanicis oblata, I.J. Adiego, J. Siles y J. Velaza (eds.), 287-295, Barcelona.

(1999): "Hispanocelta o Celtibérico", Language Change and Typological Variation: In Honor of Winfred P. Lehmann on the Occasion of His $83^{\text {rd }}$ Birthday. Vol. 1: Language Change and Phonology, E. C. Polomé y C. F. Justus (eds.), 60-77, Washington.

(2000): Indoeuropeos y no indoeuropeos en la Hispania prerromana, Salamanca.

(2001): "Indoeuropeos y no indoeuropeos en la Península Ibérica", Religión, lengua y cultura prerromanas de Hispania, F. Villar y M ${ }^{\mathrm{a}}$ P. Fernández Ảlvarez (eds), 257-283, Salamanca.

Francisco Pina Polo

Universidad de Zaragoza

e-mail:franpina@posta.unizar.es
Silvia Alfayé Villa

Universidad de Zaragoza e-mail:407616@filoz.unizar.es 
Propuesta de ubicación de los volcianos en el área prepirenaica

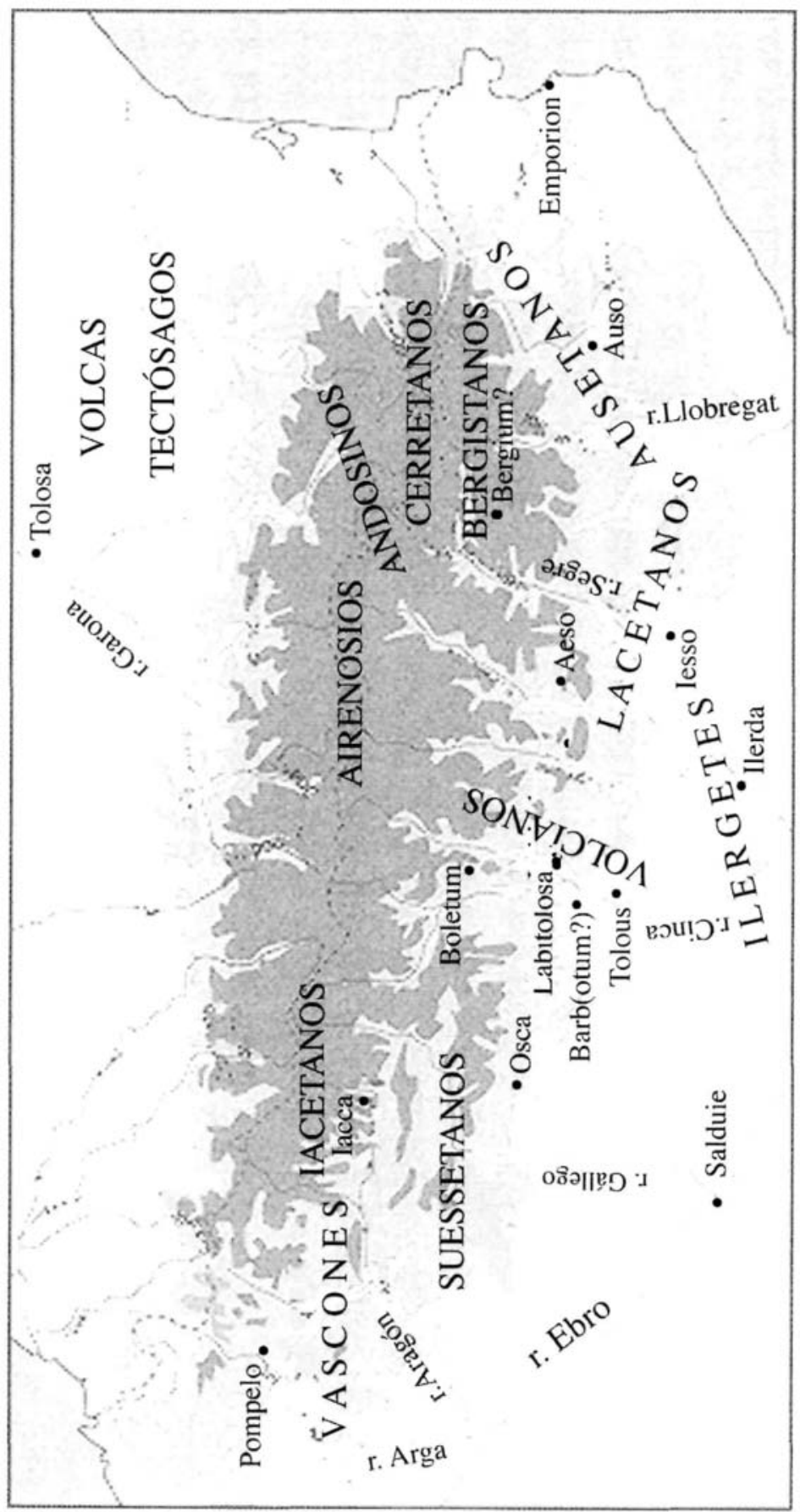

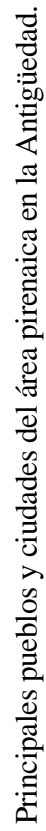

